\title{
PERSEPSI MAHASISWA TERHADAP KATERING RUMAHAN DI KOPELMA DARUSSALAM KOTA BANDA ACEH
}

(Students Perception Of Catering Home In The City Of Banda Aceh Darussalam Kopelma)

\author{
Intan Maqfirah ${ }^{1}$, Suyanti Kasimin ${ }^{1}$, T. Makmur ${ }^{1^{*}}$ \\ ${ }^{1}$ Program Studi Agribisnis, Fakultas Pertanian, Universitas Syiah Kuala
}

\begin{abstract}
Abstrak - Kebutuhan akan kehidupan yang praktis pada saat ini semakin lama semakin meningkat seperti terlihat pada kebutuhan konsumsi makanan terutama pada golongan mahasiswa. Namun persepsi mahasiswa terhadap pelayanan suatu katering merupakan penilaian menyeluruh atas keunggulan suatu jasa katering yang diukur berdasarkan kualitas, harga, cita rasa dan kebersihannya. Penelitian ini dilakukan di Kopelma Darussalam Kota Banda Aceh dengan tujuan untuk mengetahui bagaimana persepsi mahasiswa terhadap kondisi katering yang terdiri dari kualitas pelayanan, harga, cita rasa, dan kebersihan dan untuk mengetahui nilai yang paling dominan diantara empat variable kondisi katering. Populasi penelitian ini adalah mahasiswa yang berlangganan catering rumahan di Kopelma Darussalam Kota Banda Aceh dengan menggunakan metode simple random sampling. Dari hasil penelitian didapatkan bahwa persepsi mahasiswa baik terhadap usaha catering dengan nilai 4,25 dengan factor harga murah dan terjangkau yang memiliki nilai preferensi paling tinggi 4,47 .
\end{abstract}

Kata Kunci: Persepsi Mahasiswa, Katering Rumahan

\begin{abstract}
The need for the practical life at this time progressively increasing as seen in food consumption needs, especially in the group of students. but the students' perceptions of service of a caterer is a thorough assessment of the benefits of a catering service is measured by the quality, price, taste and cleanliness. This study was conducted in Kopelma Darussalam city of Banda Aceh in order to determine how students' perceptions of conditions consisting of a catering service quality, price, taste, and hygiene and to determine the most dominant value among the four variables catering condition. The study population is students who subscribe catering home in Kopelma Darussalam city of Banda Aceh using simple random sampling. The result showed that the students' perceptions both of the catering business with a value of 4.25 with cheap and affordable price factor that has the highest preference value of 4.47 .
\end{abstract}

Keywords: Student Perception, Catering Home

\section{PENDAHULUAN}

Persepsi mahasiswa terhadap kualitas pelayanan merupakan penilaian menyeluruh atas keunggulan suatu jasa. Kepuasan mahasiswa merupakan tingkat perasaan seseorang setelah membandingkan kinerja yang dia rasakan dengan harapannya (Kolter, 2000). Apabila kepuasan mahasiswa berada jauh di bawah harapan mahasiswa maka dapat dipastikan mahasiswa akan merasa bosan dan tidak ingin lagi untuk mencoba. Ukuran kualitas pelayanan yang di terima adalah tingkat perbandingan dari apa yang mahasiswa harapkan dengan apa yang di terima, dan ukuran kepuasan adalah evaluasi mahasiswa terhadap pelayanan yang diterima. 
Untuk mewujudkan dan mempertahankan kepuasan mahasiswa, perusahaan jasa dapat melakukan 4 hal yaitu mengidentifikasi siapa konsumennya, memahami tingkat harapan mahasiswa atas kualitas, memahami strategi kualitas layanan mahasiswa, dan memahami siklus pengukuran dan umpan balik dari kepuasan mahasiswa (Tjiptono, 2001). Selain itu perusahaan juga harus dapat memahami benar perilaku konsumen sasaran yaitu tindakan langsung dalam mendapatkan, mengkonsumsi produk dan jasa, termasuk proses keputusan yang mendahului dan menyusuli tindakan tersebut. Bukan tidak mungkin bahwa tindakan mahasiswa tersebut terpengaruh dari budaya dan trend yang sudah menjadi gaya hidup zaman sekarang, yang harus benar-benar di pahami oleh pengusaha jasa adalah bagaimana mereka mampu untuk menyediakan jasa yang sesuai untuk gaya hidup modern zaman sekarang.

Salah satu usaha yang berkembang dengan pesat adalah usaha katering, mengingat semakin banyaknya orang yang sudah tidak mau direpotkan dengan acara memasak untuk menjamu tamu dan berbagai acara, kebutuhan akan jasa penyedia inipun ditanggapi dengan baik oleh para pengusaha yang membuka bisnisnya disektor tata boga ini, bahkan tidak sedikit pula mereka yang beralih menjadi pengusaha katering.

Kebutuhan akan kehidupan yang praktis pada saat ini semakin lama semakin meningkat seperti terlihat pada kebutuhan konsumsi makanan terutama pada golongan mahasiswa. Keterbatasan waktu bagi mahasiswa dalam menyediakan makanan menyebabkan permintaan terhadap jasa katering semakin meningkat. Peningkatan permintaan ini sangat menguntungkan bagi pengusaha katering karena dengan banyaknya pelanggan maka semakin banyak pula keuntungan yang didapatnya.

Banyaknya usaha katering rumahan pada saat ini tidak lepas dari terampilnya para pengusaha katering tersebut melihat kesempatan besar yang ada disekitar lingkungan mahasiswa zaman sekarang yang selalu memakai sistem praktis dan cepat saji dalam urusan konsumsi, bahkan usaha katering dianggap sangat penting bagi mahasiswa mengingat keterbatasan waktu yang dimiliki oleh setiap kalangan mahasiswa. Untuk mengetahui bagaimana persepsi mahasiswa terhadap kondisi katering yang terdiri dari kualitas pelayanan, harga, cita rasa, dan kebersihan dan untuk mengetahui nilai yang paling dominan diantara empat variabel kondisi katering.

\section{METODE PENELITIAN}

Metode pengambilan sampel dilakukan dengan simple random sampling dimana peneliti dalam memilih sampel dengan memberikan kesempatan yang sama kepada semua anggota populasi untuk ditetapkan sebagai anggota sampel. Analisis data dalam penelitian ini di lakukan dengan analisis Chi-Square dan analisis deskriptif. Penelitian ini dilakukan di Kopelma Darussalam Kota Banda Aceh.

\section{Uji Chi-Square}

Uji Chi-Square yaitu untuk menentukan hubungan antara kepuasan dan persepsi mahasiswa terhadap katering rumahan. Skor kepuasan mahasiswa didapat dari hasil penjumlahan total skor kualitas pelayanan, harga, citarasa, dan kebersihan. Dengan teknik penetapan nilai skor sebagai berikut:

$\begin{array}{ll}\text { Skor tertinggi } & : \text { Jumlah pertanyaan X skor tertinggi } \\ & : 9 \times 5=45 \\ & : 45 / 45 \times 100 \%=100 \% \\ \text { Skor terendah } & : \text { Jumlah pertanyaan X Skor terendah } \\ & : 9 \times 1=9\end{array}$

Persepsi Mahsiswa Terhadap Katering Rumahan Di Kopelma Darussalam Kota Banda Aceh (Intan Magfirah, 40 Suyanti Kasimin, T. Makmur)

Jurnal Ilmiah Mahasiswa Pertanian Unsyiah, Vol. 2, No. 1, Februari 2017: 39-46 
Range (R) : : Skor tertinggi - skor terendah

: $100 \%-20 \%=80 \%$

Kategori $(\mathrm{K}) \quad: 2$ kategori $(0=$ Tidak Puas, $1=$ Puas $)$

Interval

$: \frac{R}{K}=\frac{80 \%}{2}=40 \%$

Skor Standar : $100 \%-40 \%=60 \%$

Kriteria Obyektif :

1 : Jika persentase total jawaban responden memiliki nilai $>60 \%$

0 : Jika persentase total jawaban responden memiliki nilai $\leq 60 \%$

\section{Karakteritik Mahasiswa}

\section{HASIL DAN PEMBAHASAN}

Karakterisrik mahasiswa adalah suatu keadaan mahasiswa di daerah penelitian. Karakteristik yang dimaksud dalam penelitian ini meliputi adalah karakteristik mahasiswa mahasiswa yang mengggunakan jasa katering dimana yang dilihat adalah jenis kelamin, umur mahasiswa, pekerjaan, biaya katering, dan lokasi katering yang dikonsumsi.

Tabel 1. Jumlah Mahasiswa Yang menggunakan Jasa Katering di Wilayah Kopelma Darussalam Banda Aceh Berdasarkan Jenis Kelamin, Tahun 2016.

\begin{tabular}{|c|c|c|c|}
\hline No & Jenis Kelamin & $\begin{array}{c}\text { Jumlah } \\
(\text { Orang) }\end{array}$ & $\begin{array}{c}\text { Persentase } \\
(\%)\end{array}$ \\
\hline 1. & Laki-laki & 40 & 50,0 \\
2. & Perempuan & 40 & 50,0 \\
\hline & Jumlah & 80 & 100 \\
\hline & Rata-rata & 40 & 50,0 \\
\hline
\end{tabular}

Sumber : Data Primer (diolah) Tahun 2016

Berdasarkan Tabel 1 memperlihatkan bahwa dari total 80 mahasiswa yang dijadikan sampel dalam penelitian ini, sebanyak 40 orang atau $50 \%$ dari total sampel berjenis kelamin laki-laki, serta sisanya berjenis kelamin perempuan dengan jumlah 40 orang atau 50\%. Hal ini diharapkan dapat menggambarkan alasan para mahasiswa/i dalam menggunakan jasa katering baik dari segi kualitas pelayanan, harga, citarasa, dan kebersihan.

Tabel 2. Jumlah Mahasiswa Yang menggunakan Jasa Katering di Wilayah Kopelma Darussalam Banda Aceh Berdasarkan Kelompok Umur, Tahun 2016.

\begin{tabular}{|c|c|c|c|}
\hline No & Umur Mahasiswa & $\begin{array}{c}\text { Jumlah } \\
\text { (Orang) }\end{array}$ & $\begin{array}{c}\text { Persentase } \\
(\%)\end{array}$ \\
\hline 1. & 18 Tahun & 6 & 7,5 \\
2. & 19 Tahun & 18 & 22,5 \\
3. & 20 Tahun & 49 & 61,3 \\
4. & 21 Tahun & 7 & 8,8 \\
\hline & Jumlah & 80 & 100 \\
\hline & Rata-rata & 20 & 25 \\
\hline
\end{tabular}

Sumber : Data Primer (diolah) Tahun 2016

Persepsi Mahsiswa Terhadap Katering Rumahan Di Kopelma Darussalam Kota Banda Aceh (Intan Magfirah, 41 Suyanti Kasimin, T. Makmur)

Jurnal Ilmiah Mahasiswa Pertanian Unsyiah, Vol. 2, No. 1, Februari 2017: 39-46 
Berdasarkan Tabel 2 memperlihatkan bahwa terdapat 4 kelompok umur dalam penelitian ini yaitu umur 18 tahun, 19 tahun, 20 tahun dan 21 tahun. Dimana mahasiswa terbanyak yaitu berusia 20 tahun mencapai 49 orang atau $61,3 \%$, sedangkan yang paling rendah yaitu kelompok 18 tahun hanya sebanyak 6 orang atau 7,5\%.

Biaya katering pada dasarnya disesuaikan dengan jenis menu yang dikonsumsi, oleh karena itu besar kecilnya biaya katering lebih disebabkan faktor jenis menu, oleh karena itu dalam penelitian ini terdapat 7 jenis kelompok katering yang umumnya dikonsumsi oleh mahasiswa di kawasan Kopelma Darussalam Kota Banda Aceh seperti yang terlihat pada Tabel 3:

Tabel 3. Jumlah Mahasiswa Yang menggunakan Jasa Katering di Wilayah Kopelma Darussalam Banda Aceh Berdasarkan Biaya Katering, Tahun 2016.

\begin{tabular}{|c|c|c|c|}
\hline No & Harga Katering (Rp/Bulan) & $\begin{array}{c}\text { Jumlah } \\
\text { (Orang) }\end{array}$ & $\begin{array}{c}\text { Persentase } \\
(\%)\end{array}$ \\
\hline 1. & Rp.200.000 & 2 & 2,5 \\
2. & Rp.250.000 & 4 & 5,0 \\
3. & Rp.300.000 & 13 & 16,3 \\
4. & Rp.350.000 & 18 & 22,5 \\
5. & Rp.400.000 & 17 & 21,3 \\
6. & Rp.450.000 & 25 & 31,3 \\
7. & Rp.500.000 & 1 & 1,3 \\
\hline & Jumlah & 11,40 & 100 \\
\hline & Rata-rata & & 14,28 \\
\hline
\end{tabular}

Sumber : Data Primer (diolah) Tahun 2016

Berdasarkan Tabel 3 memperlihatkan biaya katering setiap mahasiswa berbeda-beda, hal ini terlihat pada tabel 6 dimana terdapat 7 katagori harga katering, dimana paling rendah yaitu Rp.200.000 per bulan dan yang tertinggi Rp.500.000 per bulan. Adapun jumlah mahasiswa terbanyak yaitu pada harga katering Rp.450.000 per bulan dengan jumlah mahasiswa sebanyak 25 orang atau $31,3 \%$, sedangkan yang paling sedikit atau paling rendah yaitu pada harga katering Rp.500.000 per bulan dengan jumlah mahasiswa 1 orang atau 1,3\%.

Adapun harga katering rata-rata yang dikonsumsi oleh mahasiswa di kawasan Kopelma Darussalam Kota Banda Aceh yaitu Rp.376.875 per bulan. Yaitu antara harga Rp.350.000 Rp.400.000 per bulan.

Tabel 4. Jumlah Mahasiswa Yang menggunakan Jasa Katering di Wilayah Kopelma Darussalam Banda Aceh Berdasarkan Lokasi Katering, Tahun 2016.

\begin{tabular}{|c|c|c|c|}
\hline No & Lokasi Katering & $\begin{array}{l}\text { Jumlah } \\
\text { (Orang) }\end{array}$ & $\begin{array}{l}\text { Persentase } \\
(\%)\end{array}$ \\
\hline 1. & $\begin{array}{l}\text { Rencong Aceh, Jln. Inong Balee No } 39 \\
\text { Darussalam }\end{array}$ & 10 & 12,50 \\
\hline 2. & $\begin{array}{l}\text { Warkop Amar, Jln. Inong Balee No } 49 \\
\text { Darussalam }\end{array}$ & 5 & 6,25 \\
\hline 3. & $\begin{array}{l}\text { Rehani Katering, Lr. PBB No. } 28 \text { Dusun Barat } \\
\text { Darussalam }\end{array}$ & 20 & 25,00 \\
\hline 4. & $\begin{array}{l}\text { Mariamis Katering, Jln. T. Nyak Arief Lr. PBB } \\
\text { Darussalam }\end{array}$ & 15 & 18,75 \\
\hline \multirow[t]{3}{*}{5.} & Suranto Katering, Jln. T. Nyak Arief Darussalam & 30 & 37,50 \\
\hline & Jumlah & 80 & 100 \\
\hline & Rata-rata & 16 & 20 \\
\hline
\end{tabular}

Sumber : Data Primer (diolah) Tahun 2016

Persepsi Mahsiswa Terhadap Katering Rumahan Di Kopelma Darussalam Kota Banda Aceh (Intan Magfirah, 42 Suyanti Kasimin, T. Makmur)

Jurnal Ilmiah Mahasiswa Pertanian Unsyiah, Vol. 2, No. 1, Februari 2017: 39-46 
Berdasarkan Tabel 4 dapat dilihat lokasi katering para mahasiswa/i dimana semua katering ini berada di wilayah Kopelma Darussalam Banda Aceh, terdapat sebanyak 5 unit usaha yang berbentuk usaha rumah tangga. Adapun mahasiswa terbanyak pada usaha katering Suratno Katering dengan jumlah mahasiswa sebanyak 30 orang atau 37,50\%, sedangkan yang paling sedikit adalah Erna Wati (warkop Amar) dengan jumlah mahasiswa sebanyak 5 orang $(6,25 \%)$.

\section{Hasil Uji Chi-Square Kualitas Pelayanan, Harga, Citarasa, dan Kebersihan}

Uji Chi-Square digunakan untuk menjawab hipotesis 1 yaitu untuk menentukan hubungan antara kepuasan dan persepsi mahasiswa terhadap katering rumahan. Skor kepuasan mahasiswa didapat dari hasil penjumlahan total skor kualitas pelayanan, harga, dan citarasa. Dengan teknik penetapan nilai skor sebagai berikut:

$$
\begin{array}{ll}
\text { Skor tertinggi } & : \text { Jumlah pertanyaan X skor tertinggi } \\
& : 9 \times 5=45 \\
& : 45 / 45 \times 100 \%=100 \% \\
\text { Skor terendah } \quad: \text { Jumlah pertanyaan X Skor terendah } & : 9 \times 1=9 \\
& : 9 / 45 \times 100 \%=20 \% \\
& : \text { Skor tertinggi }- \text { skor terendah } \\
\text { Range (R) } \quad: 100 \%-20 \%=80 \% \\
\text { Kategori (K) } \quad: 2 \text { kategori }(0=\text { Tidak Puas, } 1=\text { Puas }) \\
\text { Interval } & : \frac{R}{K}=\frac{80 \%}{2}=40 \% \\
\text { Skor Standar } \quad: 100 \%-40 \%=60 \% \\
\text { Kriteria Obyektif }: \\
1 \quad: \text { Jika persentase total jawaban responden memiliki nilai }>60 \% \\
0 \quad: \text { Jika persentase total jawaban responden memiliki nilai } \leq 60 \%
\end{array}
$$

\begin{tabular}{|c|c|c|c|c|c|}
\hline & & & \multicolumn{2}{|c|}{ Persepsi Mahasiswa } & \multirow[b]{2}{*}{ Total } \\
\hline & & & Positif & Negatif & \\
\hline \multirow{8}{*}{$\begin{array}{c}\text { Kepuasan } \\
\text { Mahasiswa }\end{array}$} & \multirow[t]{5}{*}{ Baik } & Count & 43 & 4 & 47 \\
\hline & & Expected Count & 31.1 & 15.9 & 47.0 \\
\hline & & $\begin{array}{c}\% \text { within Kepuasan } \\
\text { Mahasiswa } \\
\end{array}$ & $91.5 \%$ & $8.5 \%$ & $100.0 \%$ \\
\hline & & $\begin{array}{c}\% \text { within Persepsi } \\
\text { Mahasiswa }\end{array}$ & $81.1 \%$ & $14.8 \%$ & $58.8 \%$ \\
\hline & & $\%$ of Total & $53.8 \%$ & $5.0 \%$ & $58.8 \%$ \\
\hline & \multirow[t]{3}{*}{ Kurang } & Count & 10 & 23 & 33 \\
\hline & & Expected Count & 21.9 & 11.1 & 33.0 \\
\hline & & $\begin{array}{c}\% \text { within Kepuasan } \\
\text { Mahasiswa }\end{array}$ & $30.3 \%$ & $69.7 \%$ & $100.0 \%$ \\
\hline
\end{tabular}

Hasil dari uji Chi-Square tersebut dengan menggunakan aplikasi SPSS dapat dilihat pada tabel berikut :

Tabel 5. Crosstabulasi Persepsi Dan Kepuasan

Persepsi Mahsiswa Terhadap Katering Rumahan Di Kopelma Darussalam Kota Banda Aceh (Intan Magfirah, 43 Suyanti Kasimin, T. Makmur) 


\begin{tabular}{|c|c|c|c|c|}
\hline & $\begin{array}{c}\text { \% within Persepsi } \\
\text { Mahasiswa }\end{array}$ & $18.9 \%$ & $85.2 \%$ & $41.3 \%$ \\
\hline & $\%$ of Total & $12.5 \%$ & $28.8 \%$ & $41.3 \%$ \\
\hline \multirow[t]{5}{*}{ Total } & Count & 53 & 27 & 80 \\
\hline & Expected Count & 53.0 & 27.0 & 80.0 \\
\hline & $\begin{array}{c}\% \text { within Kepuasan } \\
\text { Mahasiswa }\end{array}$ & $66.3 \%$ & $33.8 \%$ & $100.0 \%$ \\
\hline & $\begin{array}{c}\% \text { within Persepsi } \\
\text { Mahasiswa }\end{array}$ & $100.0 \%$ & $100.0 \%$ & $100.0 \%$ \\
\hline & $\%$ of Total & $66.3 \%$ & $33.8 \%$ & $100.0 \%$ \\
\hline
\end{tabular}

Pada Tabel 5 antara persepsi dan kepuasan terhadap 80 orang responden mahasiswa katering rumahan terdapat:

1. $91,5 \%$ kepuasan mahasiswa baik dengan persepsi positif terhadap katering rumahan.

2. $8,5 \%$ kepuasan mahasiswa baik dengan persepsi negatif terhadap katering rumahan.

3. $30,3 \%$ mahasiswa merasa kurang puas dengan persepsi positif terhadap katering rumahan.

4. $69,7 \%$ mahasiswa merasa kurang puas dengan persepsi negatif terhadap katering rumahan.

Tabel 6. Chi-Square Tests

\begin{tabular}{|c|c|c|c|c|c|}
\hline & Value & Df & $\begin{array}{l}\text { Asymp. Sig. } \\
\text { (2-sided) }\end{array}$ & $\begin{array}{c}\text { Exact Sig. (2- } \\
\text { sided) }\end{array}$ & $\begin{array}{c}\text { Exact Sig. } \\
\text { (1-sided) }\end{array}$ \\
\hline Pearson Chi-Square & $32.462^{b}$ & 1 & .002 & & \\
\hline Continuity Correction $^{\mathrm{b}}$ & 29.783 & 1 & .004 & & \\
\hline Likelihood Ratio & 34.453 & 1 & .004 & & \\
\hline
\end{tabular}

Pada tabel diatas dapat diketahui bahwa nilai Pearson Chi-Square adalah sebesar $32.462^{\mathrm{b}}$. Kemudian nilai tersebut dibandingkan dengan Chi-Square tabel yang menggunakan derajat bebas dengan rumus (baris- 1$)($ kolom- 1$)=1$.

Tabel 7. Tabel Chi-Square

\begin{tabular}{|c|c|c|c|c|c|c|c|c|}
\hline \multirow{2}{*}{ Df } & \multicolumn{7}{|c|}{$\alpha$} \\
\cline { 2 - 9 } & 0,99 & 0,95 & 0,90 & 0,50 & 0,10 & $\mathbf{0 , 0 5}$ & 0,01 & 0,001 \\
\hline 1 & 0,00157 & 0,00393 & 0,0158 & 0,455 & 2,706 & $\mathbf{3 , 8 4 1}$ & 6,635 & 10,827 \\
\hline 2 & 0,0201 & 0,103 & 0,211 & 1,386 & 4,605 & 5,991 & 9,210 & 13,815 \\
\hline Dst & & & & & & & & \\
\hline
\end{tabular}

Dari tabel di atas pada $\mathrm{df}=1$ dan $\alpha=0,05$ diperoleh nilai tabel $=3,841$. Dari nilai tersebut diketahui perbandingan $\chi^{2}$ hitung $>\chi^{2}$ tabel, sehingga dari kriteria penarikan kesimpulan diketahui bahwa tolak $\mathrm{H}_{0}$ dan terima $\mathrm{H}_{\mathrm{a}}$ yang artinya ada hubungan yang

Persepsi Mahsiswa Terhadap Katering Rumahan Di Kopelma Darussalam Kota Banda Aceh (Intan Magfirah, 44 Suyanti Kasimin, T. Makmur)

Jurnal Ilmiah Mahasiswa Pertanian Unsyiah, Vol. 2, No. 1, Februari 2017: 39-46 
signifikan antara kepuasan mahasiswa dengan persepsi mahasiswa terhadap katering rumahan.

Dengan begitu dapat disimpulkan bahwa jika konsumen merasa puas dengan nilai yang diberikan oleh produk atau jasa, sangat besar kemungkinannya menjadi pelanggan dalam waktu yang lama. Memuaskan kebutuhan konsumen adalah keinginan setiap perusahaan. Selain faktor penting bagi kelangsungan hidup perusahaan, memuaskan kebutuhan konsumen dapat meningkatkan keunggulan dalam persaingan.

Zeithaml (2003) menjelaskan kepuasan pelanggan adalah evaluasi pelanggan terhadap produk atau jasa yang diterima apakah sesuai dengan kebutuhan dan harapan pelanggan. Kegagalan untuk mempertemukan kebutuhan dan harapan yang diasumsikan sebagai ketidakpuasan dengan produk atau jasa. Lebih lanjut di katakan bahwa kepuasan pelanggan dipengaruhi oleh ciri-ciri produk atau jasa secara spesifik dan oleh persepsi terhadap kualitas.

\section{Analisis Deskriptif}

Untuk mengetahui nilai variabel mana yang paling dominan, penulis menggunakan analisis deskriptif yang digunakan untuk menganalisa data dengan cara mendeskripsikan atau menggambarkan data yang telah terkumpul (Sugiyono, 2004). Dari keempat variabel antara lain kualitas pelayanan, harga, citarasa, dan kebersihan, yang memiliki nilai paling dominan adalah harga dengan nilai preferensi 4,38 dilihat dari faktor harga sesuai dengan produk yang ditawarkan oleh jasa katering rumahan 4,51. Ini menunjukkan bahwa persepsi mahasiswa terhadap katering rumahan sangat baik karena harga yang ditawarkan sangat terjangkau dan sesuai dengan selera mahasiswa.

\section{KESIMPULAN DAN SARAN}

Berdasarkan hasil penelitian dan pembahasan maka dapat ditarik kesimpulan bahwa persepsi mahasiswa terhadap usaha katering rumahan adalah positif dengan nilai 4,25 dengan faktor harga murah dan terjangkau yang memiliki nilai preferensi paling tinggi 4,47.

Ada 4 kriteria untuk mengukur persepsi mahasiswa yaitu kualitas pelayanan, harga, citarasa, dan kebersihan. Diantara keempat kriteria tersebut, untuk kriteria yang memiliki nilai paling besar adalah harga dengan nilai rata-rata 4,38 dan kriteria yang memiliki nilai terendah adalah kebersihan dengan nilai 3,31.

Untuk kriteria harga yang memiliki nilai paling besar, dapat dilihat dari faktor harga sesuai dengan produk yang disediakan yang memiliki nilai paling besar. Selanjutnya, untuk kriteria kebersihan yang memiliki nilai kebersihan paling rendah, dilihat dari faktor nilai kebersihan paling rendah yaitu 1 .

Adapun saran yang dapat diberikan penulis dalam penelitian ini adalah untuk mendapatkan persepsi yang baik dari konsumen termasuk mahasiswa, pengusaha catering harus lebih memperhatikan lagi kebersihan tempat memasak dan kebersihan dalam penyajian makanan, serta keindahan tempat usaha katering agar mahasiswa yang berlangganan tertarik untuk mengkonsumsi dalam jangka waktu panjang.

Untuk menjaga pelanggan agar senantiasa berlangganan selalu pada catering rumahan tersebut, maka pengusaha dapat mempertahankan harga yang sesuai dengan standar kantong mahasiswa dengan maksud lain harga yang ditawarkan terjangkau dan jangan di naikkan, namun harus sesuai dengan menu yang ditawarkan, dan cita rasa yang baik tentunya mahasiswa tidak akan beralih ke jasa makanan yang lain dan tentu akan mempengaruhi persepsi calon konsumen lainnya dalam menggunakan jasa catering rumahan.

Persepsi Mahsiswa Terhadap Katering Rumahan Di Kopelma Darussalam Kota Banda Aceh (Intan Magfirah, 45 Suyanti Kasimin, T. Makmur)

Jurnal Ilmiah Mahasiswa Pertanian Unsyiah, Vol. 2, No. 1, Februari 2017: 39-46 


\section{DAFTAR PUSTAKA}

Kotler, Philip. 2000. Manajemen Pemasaran. PT. Prenhallindo. Jakarta.

Sugiyono. 2004. Metode Penelitian Bisnis: Penerbit CV. Alfabeta: Bandung.

Tjiptono, Fandy. 2001. Strategi Pemasaran. Edisi Kedua, Penerbit Andi Offset. Yogyakarta. 